\title{
EDUCAÇÃO E PARTICIPAÇÃO DOS ATORES SOCIAIS NO DESENVOLVIMENTO DE MODELO DE GESTÃO DO LIXO EM ZONA RURAL EM MINAS GERAIS
}

\author{
Maria Flávia GazZinelu ${ }^{1}$ \\ ANDREIA LOPES ${ }^{2}$ \\ Wesley Pereira ${ }^{2}$ \\ AndRÉa GAZZINELI ${ }^{3}$
}

\begin{abstract}
RESUMO: Este trabalho relata o envolvimento dos atores sociais (professores, alunos e moradores) de uma localidade rural do Estado de Minas Gerais no desenvolvimento de um modelo de gestão participativa do lixo. Trata-se de uma experiência de educação e gestão ambiental que inclui: (a) levantamento das representações e do imaginário sobre o lixo; (b) pesquisa sobre o lixo da localidade e (c) elaboração participativa de um modelo de gestão do lixo. Podese situar os resultados da educação e gestão ambiental em três níveis: em primeiro lugar, das modificações físicas ligadas à limpeza da cidade; em segundo, da construção de um novo referencial de relação dos professores e alunos com o conhecimento e, em terceiro, da mudança de postura com relação aos ambientes. Por meio de depoimentos dos professores, relatos, desenhos, mapas cognitivos dos alunos e observações das modificações físicas ligadas à limpeza da localidade, constata-se que o modelo de educação ambiental, ao articular simultaneamente instrumentos analíticos, que envolvem pesquisa e conhecimento da problemática estudada e produtores de subjetividade, cuja ênfase situa-se na relação com o ambiente nos planos figurativo e simbólico, pode favorecer aos indivíduos a criação de espaços de autonomia que Ihes permitem agir como sujeitos em seus ambientes.
\end{abstract}

Palavras-chave: educação, gestão ambiental, lixo.

\footnotetext{
1 Professora Adjunta da Universidade Federal de Minas Gerais (UFMG).

2 Bolsista de Iniciação Científica da UFMG.

${ }^{3}$ Professor Adjunto da UFMG.
} 


\section{Introdução}

A solução para o destino do lixo ainda consiste em conduzi-lo para longe, preferencialmente, para locais afastados das áreas habitadas. São os vazadouros a céu aberto, mais conhecidos como lixões, situados na periferia dos grandes centros ou nas vias de acesso aos municípios nas zonas rurais. Segundo o Censo Demográfico (1991), ainda hoje, no Brasil, de todo o lixo coletado, a maior parte vai para os lixões, embora haja variações significativas por região. No nordeste, cerca de $90 \%$ tem esse destino; no norte, quase $70 \%$; no sudeste, pouco mais de um quarto do total e, no sul, cerca de $40 \%$.

Tal alternativa indica a pouca importância, até então dada, do ponto de vista sanitário e ambiental, à questão do lixo das cidades. Reflete o conceito de que ao lixo não é atribuído valor algum. Expressão disso seria o fato dele nunca ter recebido outra conotação além daquela de inutilidade. Nesse sentido, concebê-lo como algo que encerrasse a promessa de recriação e renascimento consistiria em mera abstração.

Acontece que "esconder do olhar e tentar tornar invisível" é a idéia que, ao longo do tempo, tem inspirado os modelos de gestão de resíduos sólidos. É uma tentativa, buscando a origem do problema, de ocultar um modelo econômico que tem se comportado de forma predatória com a natureza, tratando-a como fonte ilimitada de recursos e, ao mesmo tempo, espaço inesgotável de absorção dos resíduos das atividades humanas.

$\mathrm{Na}$ esteira dos movimentos preservacionistas da década de 1960, surge a idéia da substituição dos lixões por aterros sanitários. Substituição essa que, embora reconhecida como solução viável até meados da década de 1970, não deixa de expor, com o tempo, seus limites - o espaço que exige dentro dos aglomerados urbanos e o risco de contaminação dos lençóis subterrâneos (Demajorovic, 1994).

Face a essas dificuldades, é o momento de se pensar em novas formas de gestão dos resíduos sólidos, dessa vez, direcionadas para processos de recuperação e reciclagem dos materiais. Solução, sem dúvida, inteligente, por considerar, em primeiro lugar, a finitude da matériaprima existente no planeta e, em segundo, o fato de ser "muito mais econômico fabricar uma garrafa nova com os cacos de uma garrafa quebrada, ou uma lata de refrigerante através da refundição do alumínio já beneficiado" (Idem, 1996).

A esse respeito, importante destacar a imagem de que se revestiu a reciclagem do lixo em diferentes meios. Vista como panacéia para todos os 
problemas relacionados à preservação ambiental e transmitindo uma sensação de atualidade, a reciclagem passa a ser a opção preferida daqueles que buscam aparentar uma forma "politicamente correta" de agir. Decorre daí que, até bem pouco tempo, qualquer programa de reorganização do sistema de limpeza de uma cidade, ou proposta de educação ambiental que não levasse em conta o incentivo à reciclagem - ou como se convencionou chamar, à "coleta seletiva" - estaria condenado a fracassar.

No entanto, experiências acumuladas em diferentes partes do mundo não levaram muito tempo para sugerir que as vantagens da reciclagem do lixo fossem relativizadas, uma vez que sua adoção estava necessariamente condicionada por um conjunto de aspectos, tais como a quantidade de matéria-prima disponível, a energia demandada e as ofertas de mercado, dentre outros (Bernstein, 1991).

Talvez fosse o caso de se perguntar se não seria mais racional, ao invés de se pensar unicamente em como tratar o lixo, pensar-se em como reduzir a sua produção. Por conseguinte, a partir desse raciocínio, delineia-se hoje um novo discurso sobre o lixo que privilegia menos o elo final da cadeia - o destino dado ao lixo - e mais a redução do volume de resíduos no início do processo produtivo. Assim, seja por demagogia, seja pelo gradativo aumento das preocupações com o meio ambiente, não há quem, hoje, não expresse uma preocupação crescente com os lixões e seus efeitos indesejáveis sobre o ambiente - os riscos de contaminação do solo, do ar e da água e o impacto sobre a saúde pública.

A conseqüência principal de todo esse processo é a necessidade de incidir sobre aqueles que produzem, seja as pessoas em suas residências, as instituições públicas, as empresas, as fábricas, os hospitais, estimulando a criação de uma nova cultura do lixo.

A educação pode se constituir em importante ferramenta nesse sentido. Por meio dela, torna-se possível reconstruir uma idéia do lixo mais compatível com a nova tendência mundial, pelo menos em discurso, de atuar sobre a produção do lixo. Para tanto, torna-se necessário que cada um comece com uma reflexão sobre a produção de lixo em sua casa; fique atento ao desperdício tão comum em nossa cultura e desenvolva a capacidade de julgar as razões pelas quais determinado método de tratamento do lixo é escolhido em detrimento de outro.

A mudança do discurso sobre o lixo, a inserção ativa de cada ator social no enfrentamento da problemática do lixo, o monitoramento e fiscalização das decisões dos poderes públicos com relação ao lixo são elementos essenciais num trabalho educativo que tenha, como meta, retirar as 
pessoas de um estado de impotência política, mostrando que o lixo é um problema de todos. Esta perspectiva exige que se dê a este não apenas um tratamento técnico apropriado, mas um tratamento cultural adequado.

Esse breve relance sobre as várias prioridades nos modelos de gestão de resíduos sólidos não tem como propósito suscitar um balanço técnico sobre as vantagens e desvantagens de cada um, o que fugiria do foco predominantemente cultural e educativo deste relato, mas chamar a atenção para a cultura do lixo, que vem informando sobre as diferentes modos de gestão dos resíduos sólidos e a maneira através da qual a educação pode operar no sentido de transformá-la. Assim, nosso propósito aqui é relatar uma experiência, mostrando que a educação pode vir a se constituir em "empowernment" na afirmação deste novo paradigma em vias de emergência, segundo o qual o que importa em primeiro plano é o produtor de lixo; fato que, inclusive, parece definir uma nova relação com a política.

Assim, este relato conta a trajetória dos alunos e professores de uma pequena cidade situada em zona rural que, num trabalho participativo com os moradores, trabalham e se organizam tendo em vista a (re)estruturação do modelo de gestão do lixo para a sua cidade. A tese defendida é a de que a incorporação do componente cultural e educativo no enfrentamento do problema do lixo pode possibilitar uma mudança radical no modelo de gestão de resíduos hoje utilizado em grande escala, deslocando toda a ênfase e importância para o "produtor" do lixo, ou seja, para o cidadão comum.

Trata-se do trabalho de educação e gestão ambiental desenvolvido em Boa União, distrito do município de Itabirinha de Mantena, localizada em zona rural a noroeste do Estado de Minas Gerais, no qual alunos e professores trabalham em conjunto com vistas a elaborar um modelo de gestão do lixo para a cidade. Sob muitos aspectos, esta proposta de educação e gestão pode vir a se configurar como uma importante referência para outros contextos, considerando que a situação sanitária de Boa União se parece com aquela encontrada na maior parte dos municípios de Minas Gerais e de outros estados, onde a inexistência ou ineficiência de serviço público de coleta e tratamento do lixo gera problemas de várias ordens para a população. Aliado a isso, em Boa União, pode-se citar, dentre outros, a grande incidência e prevalência de esquistossomose, o contato freqüente com as águas dos córregos contaminadas e a ausência de água encanada que contribuem para a disseminação da doença; a falta de canalização do esgoto, além do fato de que a descarga das fossas lança os dejetos nos córregos, contaminando-os. 


\section{Experiência de elaboração de modelo de gestão do lixo em Boa União}

A proposta de educação e gestão ambiental desenvolvida em Boa União distingue-se das demais intervenções usuais no campo ambiental por sustentar que educação ambiental é, antes de mais nada, educação e, por esta razão, deve estar voltada menos para a introdução de novos temas que tenham como marca a atualidade e mais para o debate contemporâneo sobre como se dá o processo de conhecer. Caracteriza-se por investir, metodologicamente falando, na articulação entre dois dispositivos de natureza distintas. Os dispositivos analíticos que envolvem a pesquisa e conhecimento da problemática do lixo de Boa União (sistema de limpeza, práticas locais, usos e hábitos) e, ao mesmo tempo, os dispositivos produtores de subjetividade, cuja ênfase está na relação com o ambiente, especificamente com o lixo, dessa vez, nos planos figurativo e simbólico.

Parte-se do suposto de que a formação de imagens mentais, representações, conhecimentos, expectativas e julgamentos são fundamentais para se compreender as relações com o meio ambiente e, em decorrência, para poder instituir ações diferenciadas sobre ele (Rio, 1996).

A abordagem utilizada é aquela na qual os alunos elaboram projetos de pesquisa e intervêm a partir de um levantamento dos problemas ambientais do lugar. Além de se inspirar nos conceitos de Dewey (1978), para o qual a educação é a própria vida e a reconstrução das experiências, e na pedagogia de Paulo Freire (1982), cuja estratégia epistemológica principal é a interação dialógica dos sujeitos entre si e com a realidade, o trabalho educativo aqui descrito representa uma tentativa de trazer, para o campo da mudança de postura com relação aos ambientes, as imagens e representações que os indivíduos constróem da sua realidade e do seu lugar, bem como a forma como interpretam suas histórias e vivências com este lugar. Desse modo, estamos levando em conta não uma única realidade, totalizante e absoluta, conforme preconiza Freire, mas as diversas configurações que assume no imaginário dos sujeitos.

Assumir estes princípios significa, no plano operacional, percorrer uma "trilha pedagógica", através da qual alunos e professores são levados a flagrarem-se com as suas imagens do lugar, de caráter figurativo e simbólico, passando, em seguida, à geração de informação sobre esse ambiente, processo, desta vez, eminentemente cognitivo, até chegar à escolha de alternativas e, finalmente, de intervenção. 


\section{Levantando percepções sobre o lixo: a primeira fase da educação e gestão}

A primeira fase do trabalho referiu-se ao levantamento das percepções sobre a situação ambiental de Boa União: o estado de limpeza das ruas, o destino do lixo domiciliar, a forma como são eliminados os resíduos líquidos dos domicílios, a distribuição da água, o esgoto a céu aberto, a contaminação dos córregos. O objetivo foi o de ajudar os alunos a flagrarem-se, através de fenômenos perceptivos, com a realidade que constróem sobre o ambiente e que configura o seu cotidiano. A exemplo de outras pesquisas sobre este tema, o instrumento utilizado foi o mapa cognitivo da situação ambiental da cidade, especificamente dos aspectos ligados ao saneamento ambiental, no qual priorizou-se o traçado mais livre e despreocupado do aluno. Como observa Downs e Stea (1977), os mapas cognitivos, além de constituírem uma representação pessoal organizada do meio físico, configuram-se como processos mentais por meio dos quais o aluno pode se apropriar dos espaços ao seu redor. O mapa cognitivo elaborado por aluno da $6^{a}$ série (Anexos - Figura 1) mostra como são eliminados os dejetos domésticos. Aparece a rede de esgoto, forma como na localidade são denominados os encanamentos que levam os resíduos líquidos domésticos diretamente para o córrego, e dois pontos de lixo situados dentro da cidade.

$\mathrm{Na}$ Figura 2, os desenhos apresentam, como destaque, cenas do cotidiano dos moradores: o lixo sendo despejado nos córregos, os dejetos domésticos sendo eliminados diretamente no córrego; o lixo sendo recoIhido do ponto de lixo da rua para a pick-up, o córrego contendo diferentes tipos de materiais, tais como tecidos, botas, brinquedos e latas.

Na Figura 3, o aluno faz em seu desenho uma projeção para o futuro e retrata como, do seu ponto de vista, Boa União poderia ter, afinal, o seu problema do lixo equacionado: cada casa passa a ter o seu latão e a cidade torna-se limpa. A esse respeito, interessante observar que 0 aluno obedece a um pensamento comum, segundo o qual a técnica é vista como principal solução para o problema e a educação e informação como estratégias auxiliares.

Dentre todos estes problemas valorizados pelos alunos, sobressaiu o do lixo. Em conversas sobre a sua relação com a cidade (onde brincam, onde gostam de ir, onde vão sozinhos ou acompanhados, o que gostam, o que decididamente não gostam na cidade), os alunos, na sua quase totalidade, expressaram uma intensa angústia com "a sujeira da cidade, das 
praças, do campo, das ruas e com o lixo espalhado por toda a cidade". $\mathrm{Na}$ tentativa de compor um quadro que representasse as percepções e tendências da coletividade com relação aos ambientes, foi aplicado um questionário com os 400 alunos da escola, em que a sujeira da cidade e a ausência de lazer foram apontados como de maior relevância do que a ausência de assistência médica e, surpreendentemente, a falta de opções de trabalho para os jovens. Conforme sublinham Alexander e Poyner (1977), a idéia de escolher tendências da coletividade como parâmetro para formulação de projetos deve ser adotada em detrimento da idéia de partir das suas necessidades, comportamento mais usual entre os pesquisadores. O seu argumento é o de que enquanto a idéia de necessidade é passiva, não implicando em ação do sujeito, a de tendência é ativa, já que reflete "o que as pessoas estão efetivamente tratando de fazer" e, por esta razão, terão mais chances de buscar a satisfação por si próprias.

Em busca de uma primeira aproximação com um dos temas escolhidos pelo aluno - o lixo, discutiu-se acerca dos seus diferentes significados, atribuídos em diferentes tempos e por diferentes culturas. Além disso, debateu-se em torno de histórias pessoais e coletivas sobre o lixo. O recurso utilizado - uma historia em quadrinhos, onde Cascão conta a trajetória de um objeto do lixão que é acidentalmente transportado por uma nave espacial para outro planeta e as reações de surpresa e interesse que tal fato desperta nos extraterrestres. Uma estratégia interessante para se debater sobre o conceito de lixo, compreender que o seu estado é apenas transitório, levantar todo o imaginário do lixo, explorar a sua poesia recorrendo, por exemplo, à metáfora: freqüentemente temos o hábito de agir com o lixo do mesmo modo que com os nossos sentimentos, empurrando para debaixo do tapete tudo aquilo que nos incomoda e para o qual, naquele determinado momento, não vemos saída.

Essas escolhas metodológicas devem-se ao fato de que estabelecer um contato com o problema num plano mais simbólico é fundamental, quando a meta é a mudança de postura dos indivíduos. Sabemos que a relação dos indivíduos com o ambiente e com a saúde expressa suas crenças, valores e representações, tanto as individuais, relacionadas com as suas histórias pessoais, como as coletivas, construídas independentemente do indivíduo. Traduz não apenas isso, mas também o conhecimento e nível de informação sobre o tema, processos que devem fazer parte da próxima etapa da educação e gestão ambiental. 


\section{Gerando informação sobre o lixo de Boa União: a segunda fase da educação e gestão ambiental}

Após este olhar introdutório sobre a situação ambiental da cidade, era preciso conhecer melhor o problema. Dava-se início à segunda etapa da educação e gestão, na qual alunos e professores se envolveram num trabalho colaborativo de geração de informação sobre o lixo de Boa União. Na tentativa de compreender o problema, os alunos realizaram observações e entrevistas com moradores e com o pessoal responsável pelo sistema de limpeza da cidade. Durante 15 dias, foram feitas rondas nas ruas da cidade, observando práticas locais relacionadas ao lixo. O objetivo foi o de levantar informações precisas sobre a varrição, horário e dia em que é feita a coleta, como e onde o lixo é depositado.

Assim, a partir destes instrumentos utilizados, foi possível constatar que o lixo de Boa União é depositado sem qualquer acondicionamento, sendo a maior parte no quintal (34\%), nos pontos de lixo mais próximos $(31 \%)$ e em frente de casa, diretamente no chão $(25 \%)$. O mapa elaborado por aluno da $7^{\mathfrak{a}}$ série, no início do trabalho, sob orientação da professora de Geografia, após visita de observação à cidade, confirma tais resultados ao revelar o excessivo número de pontos de lixo (locais onde a população costuma acumulá-lo para ser coletado) espalhados pela cidade (Figura 4). Além disso, foi possível concluir, a partir das entrevistas e ronda por todas as ruas, que não há regularidade no sistema de varrição de Boa União. Constatouse que tal procedimento é realizado de forma desigual na cidade, concentrando nos pontos centrais das ruas mais importantes do distrito onde predominantemente flui o tráfego da cidade. Este mesmo problema foi identificado em relação à coleta do lixo que acontece, algumas vezes, na área central do distrito, ao contrário da região periférica, onde o lixo fica acumulado. A Figura 5 ilustra bem as duas regiões distintas em Boa União: a região central sempre limpa e a periferia com lixo acumulado.

À inexistência de um sistema regular de coleta de lixo pela Prefeitura, superpõe o fato de que a população não sabe informar o dia e o horário em que preferencialmente o caminhão que realiza a coleta passa nas ruas, ponto considerado como o mais crítico pelos moradores, conforme depoimento em seguida:

"Quem não tem condições de comprar essas sacolas próprias para colocar o lixo, deve receber da Prefeitura. Se a Prefeitura não tem condições de fornecer porque são muitos moradores, então deve colocar em latões 
colocados na rua, onde tem maior freqüência de lixo. O pessoal que recolhe o lixo deveria ter um dia certo para transportar o lixo com a pickup e que fosse avisado para as pessoas, para conscientizar o nosso povo, dia X é o recolhimento do lixo. Então eu sabendo disso, a minha esposa sabendo disso, ela vai varrer o terreiro, ela vai dar uma vasculhada lá na dispensa no dia certo".

Ao mesmo tempo, ainda na segunda etapa da pesquisa, havia necessidade de obtenção de dados qualitativos e quantitativos do lixo de Boa União. Os alunos, então, participaram, com a ajuda de um especialista, de um diagnóstico quali-quantitativo do lixo da cidade. O especialista reconstituiu um dia de coleta na cidade e separou os materiais do lixão para pesagem. Por sua vez, os alunos, em conjunto, convencionaram uma forma de medida da massa dos componentes do lixo da sua casa.

Uma análise destes levantamentos mostrou, de forma surpreendente, que a quase totalidade do lixo recolhido pelo sistema de limpeza pública $(95 \%)$ é composta por folha e terra, conforme mostra o gráfico exposto em mural na escola e exaustivamente debatido pelos alunos de todas as séries (Figura 6).

A própria necessidade dos moradores e serventes da Prefeitura de deixar os quintais e a frente da casa limpos e a inexistência de recipientes adequados para acondicionar o lixo nas ruas fazem com que a varrição por eles realizada acumule grande quantidade de terra e folhagem nos pontos de lixo que se formam até o dia da coleta pela Prefeitura.

Visando superar esse conjunto de dificuldades detectadas e colaborar para a reestruturação do sistema de limpeza de Boa União, alunos e professores iniciam, sob a orientação do especialista, um estudo sobre o lixo: o que é, de onde vem, tipos de lixo, a política dos 3R (redução, reutilização e reciclagem), o papel da indústria, o consumismo, a propaganda, a situação do lixo em Belo Horizonte, em outros países desenvolvidos e subdesenvolvidos e também sobre aspectos técnicos relacionados à limpeza, coleta, destinação e tratamento final do lixo. Conhecer apenas a situação de Boa União parecia insuficiente para a busca de respostas às questões e hipóteses levantadas. Era preciso munir o aluno de ferramentas; levá-lo a pensar nele próprio não apenas como produtor de lixo, mas, sobretudo, como agente capaz de interferir no destino final do lixo. O texto abaixo, elaborado por aluna de $7^{\underline{a}}$ série após aula sobre "o lixo e seus problemas, responsabilidade nossa", expressa bem o discurso que informou e direcionou o conjunto de estudos teóricos sobre o lixo: 
"O lixo pode ser prejudicial à nossa saúde, ele pode causar doenças e outras coisas. Algumas coisas antes de transformá-las em lixo têm utilidade para nós, mas preferimos jogá-las fora. Jogamos o lixo em lugares que não devemos e não nos importamos com aquilo, mas, com o passar do tempo, o lixo vai se acumulando até não agüentarmos mais e aí começamos a falar do lixo e dos problemas que o lixo nos causa e esquecemos que quem jogou aquele lixo ali fomos nós e se aquele lixo está ali é por nossa irresponsabilidade".

Dando prosseguimento ao trabalho de instrumentalizar o aluno, foram realizadas oficinas, nas quais alunos e professores tiveram oportunidade de pensar sobre os dados de Boa União, com base nas informações técnicas; refletir sobre os limites e possibilidades de cada opção e sobre a sua adequação face às condições sociais, econômicas e culturais da cidade. Como resultado de um procedimento no qual todos estes aspectos foram levados em conta, pode-se citar a resolução do grupo de montar um sistema de compostagem orgânica, na escola, em caráter experimental, tendo em vista a necessidade de corrigir este procedimento largamente utilizado pelos moradores em seus domicílios. O fato dos moradores utilizarem restos de alimento na adubação dos terrenos ou na alimentação dos porcos ou cachorros faz com que não ocorra um processo mais grave e irremediável de contaminação dos lençóis subterrâneos no local onde se situa o lixão da cidade. No entanto, tal procedimento domiciliar, embora aceitável quando se analisa do ponto de vista do efeito nefasto da sua deposição no lixão, ainda tem sido realizado sem nenhuma atenção às regras biológicas de aeração e impermeabilização. Importante ressaltar que tal consenso do grupo para o equacionamento do problema não seria possível, caso professores e alunos não tivessem, ao mesmo tempo, domínio sobre comportamentos dos moradores e sobre formas corretas de tratamento do lixo orgânico.

Um diagnóstico deste tipo é eficaz, na medida em que integra a visão de especialistas com as experiências e comportamentos dos moradores. Segundo Castello (1996), com base em experiências de percepção ambiental desenvolvidas em Porto Alegre, esse tipo de diagnóstico pode garantir alto grau de legimitidade ao que se vier a propor para a melhoria da qualidade ambiental, uma vez que, além de próximo das expectativas dos moradores, permite que eles próprios, no ato de projetar, possam ir, ao mesmo tempo, se educando e se transformando. Ao que tudo indica, alunos e professores encontravam-se mais aptos para decidir, escolher, opinar, criticar e julgar. Após rever noções e representações sobre o lixo, estudar o problema, analisar onde efetivamente se localizam seus pontos 
críticos, alunos e professores tornam-se capazes de selecionar alternativas de ação, capacidade indispensável ao exercício de cidadania.

\section{Analisando as demandas, agindo e obtendo alguns frutos}

Era preciso, a partir deste momento, transformar todo este acervo de conhecimentos e experiências em argumentos e ações, pois o cerne do trabalho de educação e gestão ambiental situa-se entre a força do pensar e a força do fazer. Tinha início a terceira etapa do trabalho de educação e gestão ambiental.

Dando prosseguimento ao plano traçado, alunos e professores realizaram uma reunião com o prefeito, na própria escola, para apresentar a pesquisa feita e solicitar apoio no sentido de equacionar os problemas constatados. $O$ evento foi aberto ao público e, como toda atividade que tem lugar na escola, contou com a presença significativa da população. O inventário realizado pelos alunos foi apresentado e exposto em mural na escola - as tabelas, gráficos, textos, desenhos, estórias e fotos que contam sobre o lixo de Boa União. Posteriormente, um representante dos professores leu as solicitações para a prefeitura - a aquisição de latões para a cidade e a regularização dos seus itinerários de limpeza e coleta de lixo. A Tabela 1, que indica o número de latões necessários para a cidade, cálculo feito durante exercício de matemática a partir de dados que mostram, tecnicamente, qual a relação ideal entre cumprimento da rua e distância entre latões, mostra um exemplo de uma produção exposta no mural.

Este encontro entre o pessoal da escola e o prefeito configurouse, antes de mais nada, como uma aula para todos os presentes. Uma aula diferente das que usualmente ocorrem dentro da escola, pois nela os processos interlocutivos eram mediados não só pelos conhecimentos prontos presentes no livro-texto, mas, sobretudo, pelos conhecimentos construídos pelos alunos.

Após dois meses da reunião com o prefeito, Boa União recebe parte dos latões solicitados. Estes, como não foram em número suficiente, são distribuídos pela cidade de forma irregular, ficando algumas ruas sem recipiente para acondicionar o lixo. Transcorridos seis meses após a reunião e dezoito meses de trabalho educativo, verificou-se, a partir de observações dos alunos nas suas respectivas ruas, sob orientação dos professores, que a coleta semanal do lixo passou a ocorrer em um mesmo dia da semana, fato que, segundo opinião dos professores, ainda não 
era do conhecimento de todos os moradores. Constatou-se, também, que vários dos importantes pontos de lixo da cidade foram eliminados, o que pode ser visto ao compararmos o mapa da Figura 4, confeccionado em 1997, e o mapa traçado no início de 1999 (Figura 7). Com relação ao sistema de varrição, detectou-se que as ruas, de uma forma geral, passaram a ser varridas pelo menos uma vez por semana.

Contudo, as mudanças não ficaram apenas no plano da limpeza urbana. Observou-se também por parte dos alunos, segundo depoimento dos professores, uma mudança de postura que se traduziu em um maior cuidado geral com a limpeza da escola. Foram confeccionadas lixeiras pelos professores que passaram a ser rigorosamente utilizadas pelos alunos. De acordo com seu ponto de vista, são mudanças gerais que se observam simultaneamente em diversos lugares - casa, rua, praça, escola. Veja alguns depoimentos dos professores:

"Na escola, os meninos estão mais conscientes e não jogam lixo no chão. Às vezes, eles mesmos querem lavar o chão e a sala. Eles brigam uns com os outros quando há lixo no chão".

"Hoje é proibido jogar lixo perto da quadra. Antes lá era um ponto de lixo, um depósito de lixo".

"Está difícil este negócio do lixo porque os meninos sempre falam: olha lá o outro jogando papel no chão".

"Hoje as ruas estão mais limpas. Há os latões. Mas há ainda pequenos problemas".

Chegou-se à fase de analisar estes resultados e decidir sobre os novos rumos para o projeto. Os professores, demonstrando maior familiaridade com este processo dinâmico de identificar as demandas e definir etapas de trabalho, afirmam que o que falta para avançar no processo de reestruturação do sistema de limpeza é a participação dos moradores, o que pode ser conseguido por meio de um trabalho educativo a eles destinado. Tal observação está ligada ao fato de que, do seu ponto de vista, embora o número de latões esteja longe do ideal, e, do mesmo modo, a freqüência com que a varrição da cidade é realizada, o problema maior ainda está no comportamento do morador que, além de ignorar o dia da coleta e não planejar a limpeza da sua casa, deposita o lixo no ponto mais próximo logo depois que a pick-up passa fazendo a coleta. O "desabafo" de um dos professores exemplifica este modo de pensar: 
"Uma grande parte da população sabe que a coleta é na sexta-feira. Mas uma minoria não sabe. Meus vizinhos, pelo menos, sabem que a coleta é na sexta, por isso eu fico 'pê da vida'... O Isaías acaba de passar com a pick-up, eu não sei de onde tiram tanto lixo que você pode ir lá que está amontoado na beirada daquele muro do meu lote ali!!! Quer dizer, ele acabou de tirar o lixo, eles vão lá e despejam no mesmo lugar!!!"

O trecho extraído de uma discussão entre os professores, durante planejamento, ilustra o raciocínio que foi sendo tecido até se chegar à opção por um trabalho educativo junto aos moradores:

"Ali no Gilson perto da minha casa tem um latão, eu não vou colocar o meu lixo e colocar lá no latão dele, o latão não comporta nem o lixo da venda dele. Eu junto no meu quintal, pois na rua da minha casa só tem latão ali prá baixo." (Professor 1)

"O problema está então no latão?" (Professor 2)

"São poucos latões, igual aquele dia que nós fizemos o levantamento e foi pedido 50 ou 60 latões. Conseguiram 20. 1/3 do que foi pedido! Então quer dizer que se a gente conseguir mais melhora, né?" (Professor 3 )

"Melhora, mas eu acho que a conscientização da população é o centro. É isso que a escola pode fazer, né? Este trabalho é nosso. É a nossa contrapartida. E a prefeitura aí pode aumentar o latão." (Professor 4)

Os mapas dos pontos de lixo constituem prova contundente desse comportamento dos moradores. Observa-se a existência de pontos de lixo próximos aos latões, fato que só pode ser explicado através das motivações e tendências dos moradores. Nesse ponto preciso, Rio (1996) afirma que tentar compreender a forma como os indivíduos percebem e relacionam-se com seus espaços e problemas do cotidiano implica buscar lidar com a sua subjetividade, ou seja, com a satisfação humana e com as condutas resultantes.

Desse modo, cabe, sem dúvida, neste momento, indagar sobre as razões de tal comportamento. Os professores, em conversas informais, revelam algumas pistas sobre as razões que, do seu ponto de vista, estariam motivando os moradores a agir desse modo. Uma das razões pode estar situada na insatisfação com a solução encontrada pelos professores e acatada pela prefeitura de colocar latões de lixo nas ruas, con- 
forme depoimento: "eu não gostaria de latão em frente da minha casa, pois as pessoas não usam sacos plásticos e fica um cheiro horroroso!"

Outra razão para esta ação desobrigada dos moradores é a "política", tal como experienciada pelos moradores. Entendida por eles como o conflito entre os dois partidos existentes na cidade, "a política", conforme designação por eles utilizada, é o acontecimento que, no dia-a-dia, informa, regula e inspira todas as suas ações e sentimentos com relação à cidade. De acordo com os professores, a aprovação ou reprovação de uma decisão ou escolha na cidade não é feita com base na sua pertinência técnica, mas sim na dependência do partido do qual partiu a iniciativa.

Dentro desta perspectiva, o próximo passo será o de averiguar as atitudes e comportamentos da população frente a decisões de gestão que afetam suas vidas. Particularmente, com relação àquelas elaboradas a partir das expectativas e experiências dos moradores e, de forma cooperativa, com os professores e alunos da Escola Amâncio Sobrinho. Isso está relacionado com outra esfera de percepção, ou seja, com a percepção que os usuários têm a respeito de seu próprio potencial de participar de decisões que atingem seu ambiente coletivo.

\section{Considerações finais}

Procurou-se, neste artigo, buscar mostrar que a educação, ao articular instrumentos, ao mesmo tempo analíticos e produtores de subjetividade, pode favorecer aos indivíduos a criação de espaços de autonomia que Ihes permitam agir como sujeitos em seus ambientes. Para isso, toma-se como exemplo o tema do lixo. Primeiramente, o texto mostra de que forma a educação pode contribuir para a construção de subjetividades compatíveis com uma nova cultura do lixo que põe ênfase no produtor do lixo, portanto, no cidadão comum. Em outras palavras, exemplifica como a educação pode fazer com que a nova cultura do lixo não permaneça apenas como recurso de retórica. Em segundo lugar, procura descrever o trabalho de educação e gestão ambiental incidindo sobre a (re)estruturação participativa do sistema de limpeza da cidade de Boa União, situada em zona rural em Minas Gerais.

Pode-se situar os resultados da educação e gestão ambiental em três níveis. O primeiro, mais facilmente observável, refere-se às modificações físicas ligadas à limpeza da cidade - o desaparecimento de pontos de lixo tradicionais na cidade, a conquista, por parte dos 
professores e alunos, dos latões para acondicionamento do lixo e a regularização da coleta e varrição, principal queixa dos moradores.

O segundo, inserido num campo mais pedagógico, refere-se à construção de um novo referencial de relação dos professores e alunos com o conhecimento, com o registro escrito e com a fala. Ao valorizar a investigação e geração de informação, a percepção ambiental, a produção textual e a argumentação, em diferentes contextos e instâncias, a educação e gestão ambiental permitem que os alunos produzam significados e percebam que o conhecimento não é algo acabado, fato que vem auxiliar na superação dos tão falados estereótipos das produções escolares. Nesse sentido, as atividades desenvolvidas pelos alunos, que no dia-a-dia da escola nada lhes dizem, adquirem aqui um sentido especial: o texto não é escrito para que apenas o professor de português o leia e corrija; o desenho não é confeccionado apenas para a apreciação do professor de artes; o biIhete não é feito apenas para o treinamento em modalidades textuais, mas, antes de mais nada, para lhes favorecer a concretização dos seus projetos pessoais e coletivos. Como conseqüência, o que se observa é que alunos e professores vão aprendendo a confiar nas suas possibilidades de escritores, oradores e, sobretudo, de atores sociais em situações verdadeiras de interação e intercâmbio. Coerentemente, ao que tudo indica, todo este trabalho vem permitindo também aos professores se envolverem num processo de redimensionamento epistemológico da sua prática pedagógica.

O terceiro nível refere-se à mudança de postura com relação aos ambientes. Observa-se que, além dos exemplos anteriormente descritos que mostram uma nova relação dos alunos com o espaço da escola, há o reconhecimento, por parte dos professores, do seu papel educativo, ao lado daquele que cabe aos órgãos governamentais, de catalisar o incremento do nível de conhecimento dos moradores com as conseqüências significativas para a gestão participativa. Já com relação aos moradores, é imprescindível ressaltar a importância de um trabalho como este, no qual alguns aspectos ligados ao fenômeno da gestão ambiental - como, por exemplo, o fato do indivíduo se desincumbir da sua parcela de participação nas características ambientais do seu lugar, resistindo a se organizar como cidadão -, já intensamente discutidos pela literatura, podem ser aqui verificados de forma empírica.

Recebido para publicação em 15 de março de 1999. 


\title{
EDUCATION AND PARTICIPATION OF SOCIAL ACTORS \\ IN THE DEVELOPMENT OF A REFUSE MANAGEMENT MODEL IN aN RURAl area of Minas Gerais (Brazil)
}

\begin{abstract}
This work reports on the involvement of social actors (teachers and students) from a rural area en the State of Minas Gerais, Brazil, in the development of a program for participative management of city refuse. This program of education and environmental management included: a) investigation of teachers and students representations' about refuse; $b$ ) research about the city's refuse situation; c) development of a participative program of local refuse management. We present results from three levels: a) observations of improvements about the city's refuse situation; b) construction of new parameters in the relationship between teachers and students with their knowledge; c) change in the teachers and students attitudes' towards the environment. Through the written work, drawings and cognitive maps of students, and observations of improvements in the cleanliness of the local environment, we conclude that this program which involves research and analysis of the environmental problems, with subjectivity producing instruments can contribute to the organization of spaces of autonomy which enable individuals to modify their environment.
\end{abstract}

Key words: education, environmental management, refuse.

\section{Referências bibliográficas}

ALEXANDER, C e POYNER, B. Los Atomos de la Estructura Ambiental. Summarios, 7(1), 1977.

BERNSTEIN, J. Alternative approaches to pollution control and waste management regulatory and economic instruments. Washington: World Bank (Discussion Paper).

CASTELLO, L. A percepção em análises ambientais. In: RIO, V. e OLIVEIRA, L. Percepção ambiental: A experiência brasileira. São Carlos: Editora Universitária, Universidade Federal de São Carlos, 1996. 253p.

CENSO Demográfico. Resultados do universo relativos às características da população e dos domicílios nำ1 - Brasil. Rio de Janeiro: IBGE, 1991.

DEMAJOROVIC, J. A evolução dos modelos de gestão dos resíduos sólidos e seus instrumentos. In: "Política ambiental e gestão dos recursos naturais", Cadernos Fundap, maio/ago. 1996. 
"Meio Ambiente e resíduos sólidos: Avanços e limites na cidade de Viena e lições para São Paulo". Dissertação de Mestrado, Escola de Administração de Empresas de São Paulo, Fundação Getúlio Vargas, 1994.

DEWEY, J. A pedagogia de Dewey. In: Vida e Educação. São Paulo: Melhoramentos, 1978. 45p.

DOWNS, Roger e STEA, David. Maps in minds: Reflection on cognitive mapping. Nova lorque: Harper e Row, 1977.

FREIRE, P. Ação cultural para a liberdade. 6aㅡ ed. Rio de Janeiro: Paz e Terra, 1982. 149p.

RIO, V. Cidade da mente, cidade real. In: RIO, V. e OLIVEIRA, L. Percepção ambiental: $A$ experiência brasileira. São Carlos: Editora Universitária, Universidade Federal de São Carlos, 1996. 253p. 


\section{ANEXOS}

\section{Figura 1}

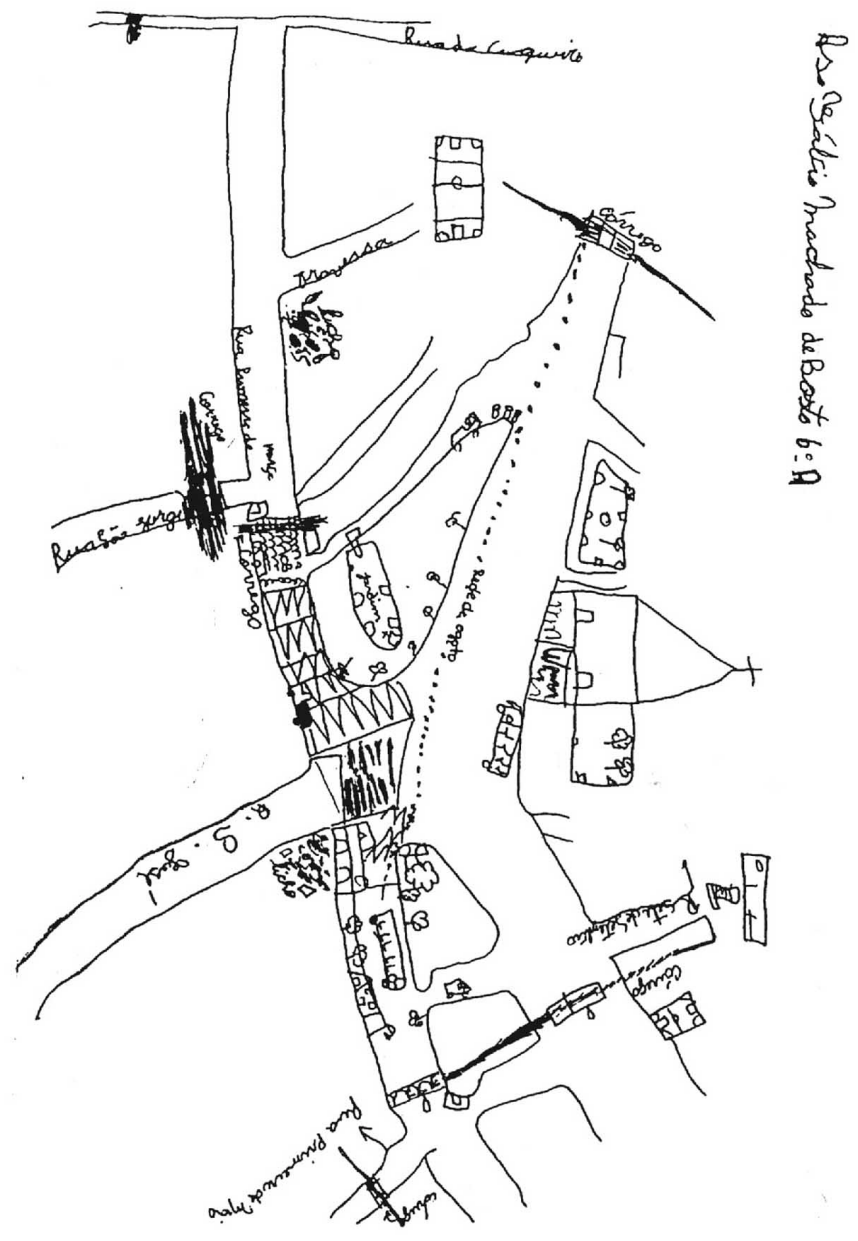

Mapa cognitivo elaborado por aluno da $6^{a}$ série, mostrando como são eliminados os dejetos domésticos em Boa União. Aparece a rede de esgoto, forma como na localidade são denominados os encanamentos que levam os resíduos líquidos domésticos diretamente para o córrego e dois pontos de lixo situados dentro da cidade. 


\section{Figura 2}

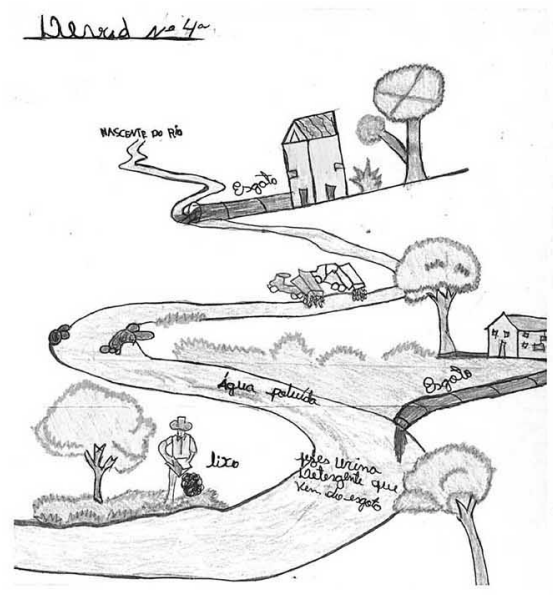

gation $\frac{25}{\frac{04}{97}}$ sérid $3^{\circ} A$
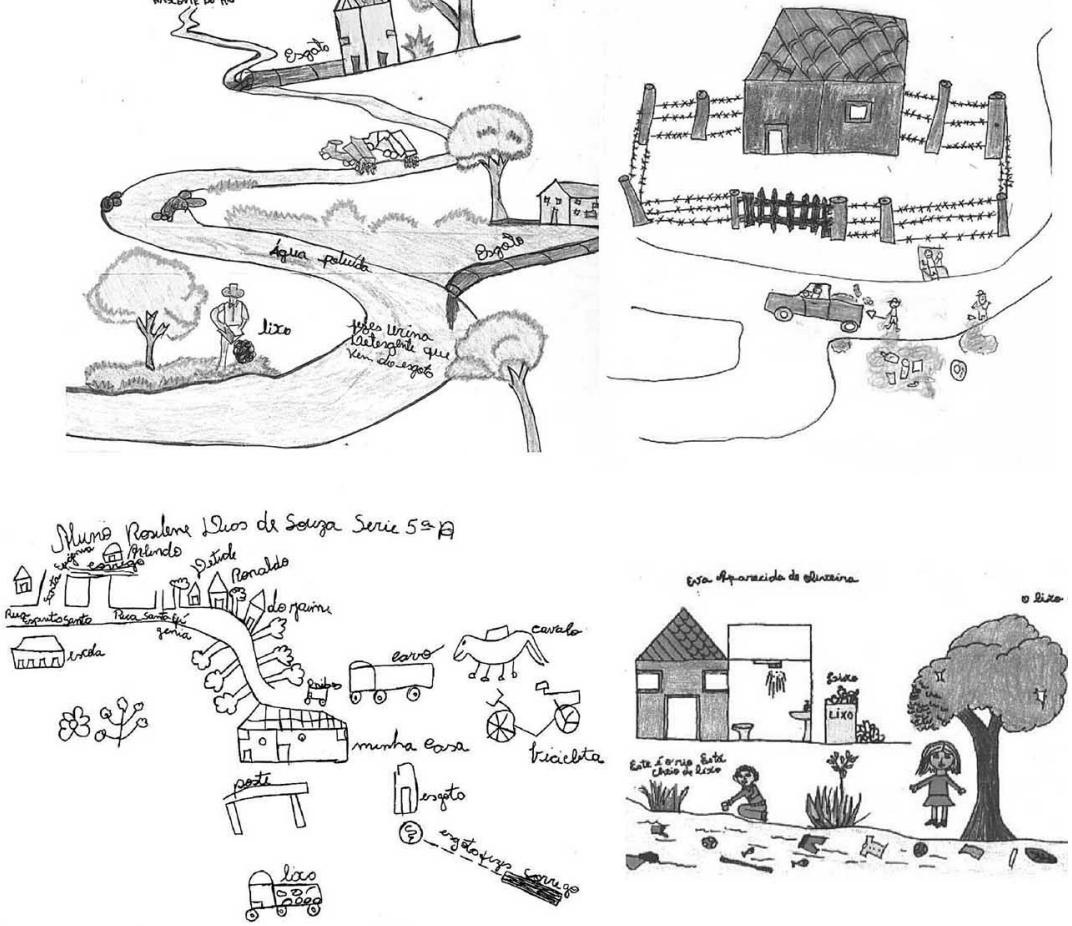

Cenas do cotidiano dos moradores: o lixo sendo despejado nos córregos, os dejetos domésticos sendo eliminados diretamente no córrego; o lixo sendo recolhido do ponto de lixo da rua para a pick-up, o córrego contendo diferentes tipos de materiais, tais como tecidos, botas, brinquedos e latas. 
Figura 3

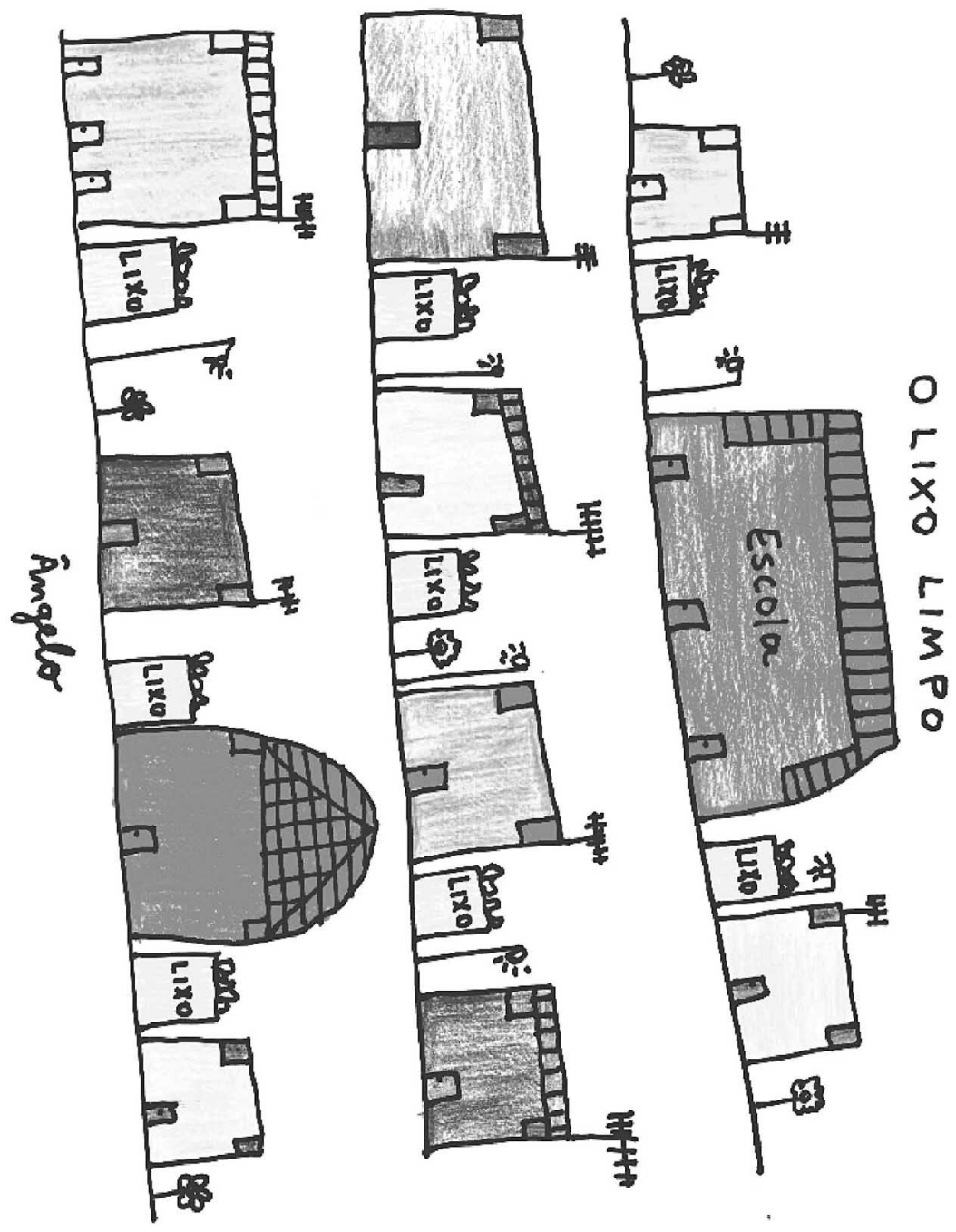

Projeção para o futuro da situação de limpeza de Boa União confeccionada por aluno da $7^{a}$ série. 


\section{Figura 4}

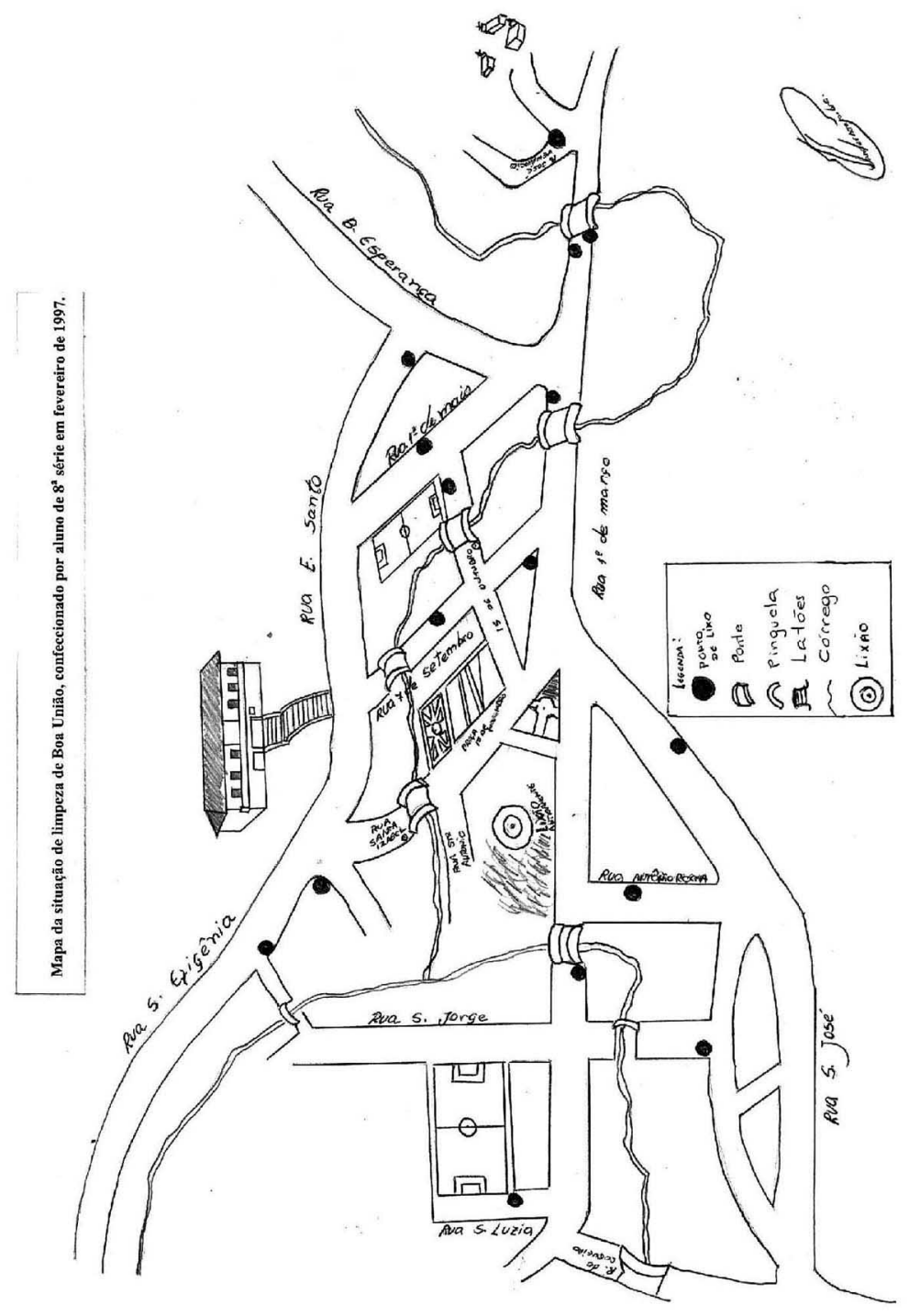

Mapa elaborado por aluno da $7^{\text {a }}$ série (fevereiro de 1997), após visita de observação à cidade, revelando o excessivo número de pontos de lixo espalhados pela cidade 


\section{Figura 5}

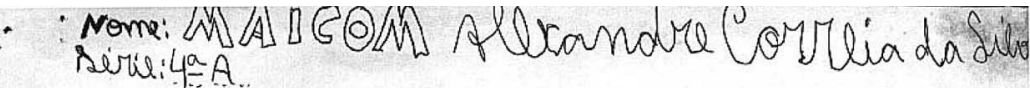
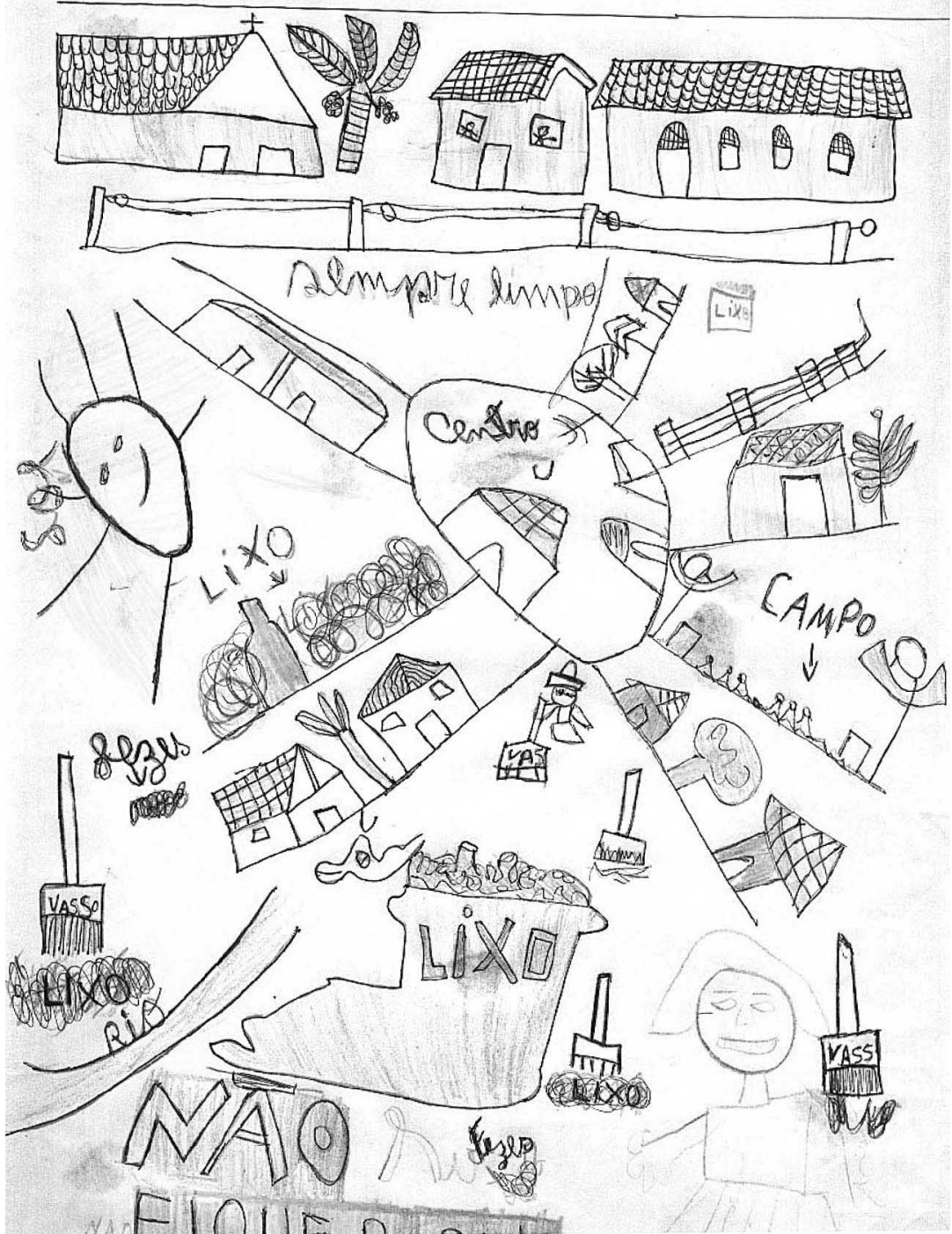

Distribuição da limpeza e coleta de lixo em Boa União, ilustrando duas regiões distintas na cidade: a central, sempre limpa, e a periferia, com lixo acumulado. 
Figura 6

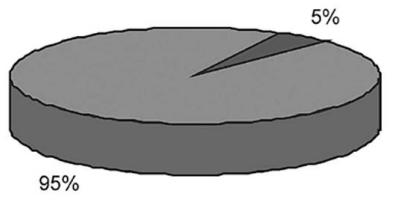

Terra e folhagem

Outros

Análise de levantamentos da composição do lixo de Boa União, mostrando que a quase totalidade do lixo recolhido pelo sistema de limpeza pública (95\%) é composta por folha e terra.

\section{Tabela 1}

\begin{tabular}{|l|c|c|c|}
\hline \multicolumn{4}{|c|}{$\begin{array}{c}\text { Levantamento do número de latões necessários } \\
\text { para Boa União }\end{array}$} \\
\hline Rua & \multicolumn{2}{|c|}{ Medida } & $N^{\circ}$ de \\
\hline & comprimento & largura & latões \\
\hline Santa Luzia & 48 & 10 & 1 \\
\hline 7 de Setembro & 169 & 8 & 2 \\
\hline 15 de Outubro & 98 & 9 & 1 \\
\hline São José & 390 & 9 & 4 \\
\hline Antônio Rocha & 103 & 6 & 1 \\
\hline Praça & 281 & & 3 \\
\hline Boa Esperança & 200 & 10 & 2 \\
\hline Espírito Santo & 440 & 11 & 4 \\
\hline Coqueiro & 600 & 10 & 6 \\
\hline Travessa ${ }^{\circ}$ Maio & 92 & 6 & 1 \\
\hline $1^{\circ}$ Maio & 400 & 12 & 4 \\
\hline Santo Antônio & 118 & 7 & 1 \\
\hline Santa Isabel & 55 & 7 & 1 \\
\hline Santa Efigênia & 324 & 9 & 3 \\
\hline Beco do Romão & 61 & 4 & 1 \\
\hline $1^{\circ}$ de Março & 609 & 11 & 6 \\
\hline São Jorge & 163 & 10 & 2 \\
\hline Total & & & 43 \\
\hline
\end{tabular}

Número de latões necessários para Boa União - o cálculo foi feito durante exercício de matemática. 


\section{Figura 7}

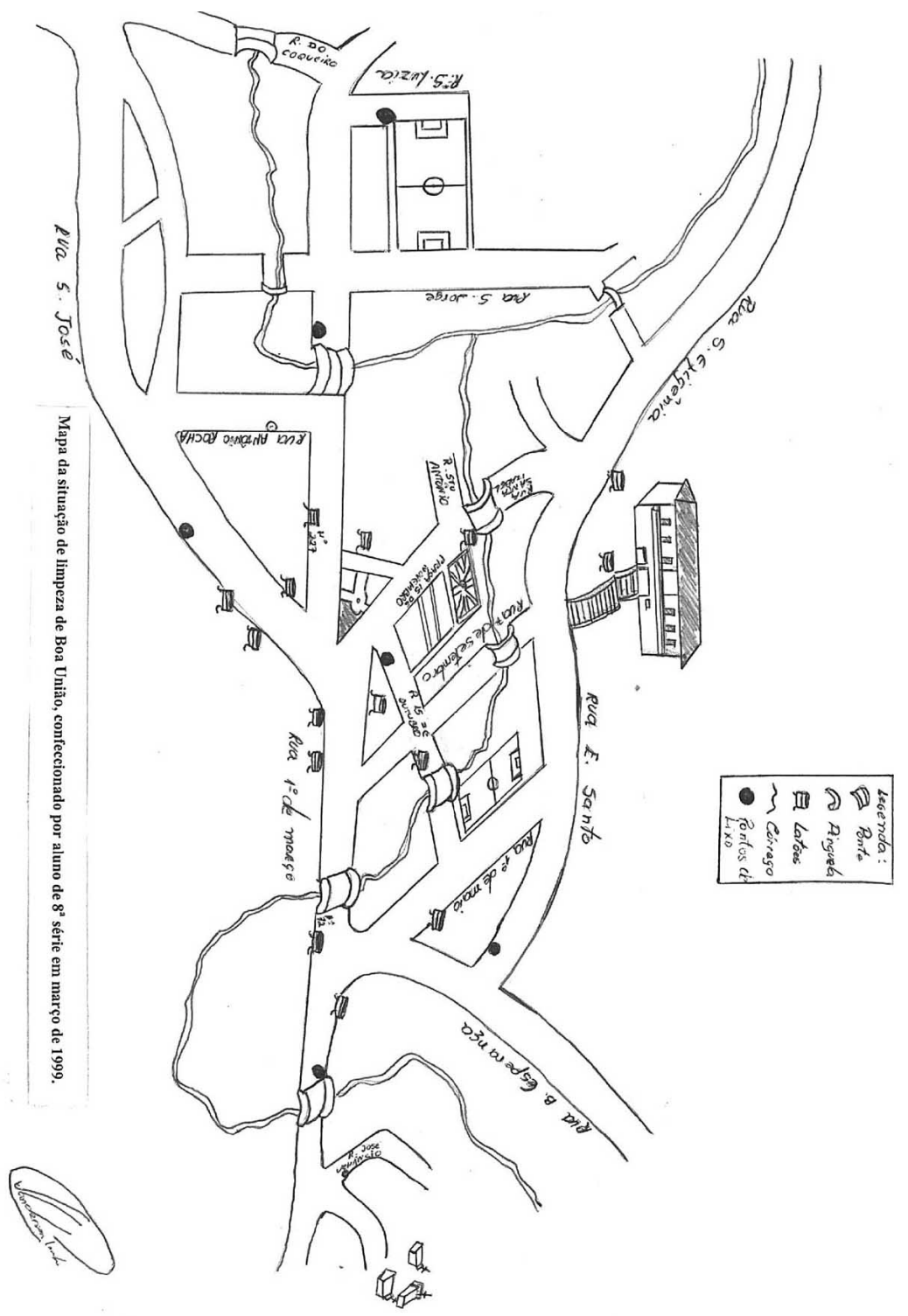

Mapa dos pontos de lixo de Boa União, em março de 1999, mostrando a diminuição destes. 